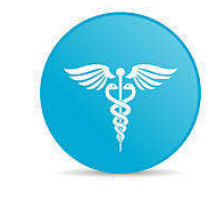

International Journal of Advances in Pharmacy and Biotechnology

Vol.1, Issue-4, 2015, 7-14

Research Article

Open Access.

I J A P B

ISSN: $2454-8375$

\title{
FORMULATION AND IN-VITRO EVALUATION OF METRONIDAZOLE MEDICATED DENTAL GEL
}

\section{Devandla Adukondalu1*, Pendiyala Rani Rudrama Devi', Kulandaivelu Umasankar2, Challa Srinivas Reddy³, Yamsani Shravankumar', Yamsani Madhusudan Rao'.}

\author{
${ }^{1}$ Department of Pharmaceutics, Vaagdevi College of Pharmacy, Hanamkonda, Telangana-506001. \\ 2Department of Pharmaceutical Chemistry, Vaagdevi College of Pharmacy, Hanamkonda, Telangana-506001. \\ ${ }^{3}$ Department of Pharmacognosy, Vaagdevi College of Pharmacy, Hanamkonda, Telangana-506001. \\ *Corresponding author e-mail: devandlaadukondalu@gmail.com
}

Accepted: 16 November 2015

\begin{abstract}
:
The present research work planned to prepare medicated therapeutic dental gel for the treatment of periodontal infection and dental caries. Metronidazole was choosen as model drug due to its wide spectrum of antimicrobial activity, low toxicity and high efficacy against bacteria. The dental gel was prepared by dispersion method using different natural bio-degradable polymers Chitosan, Xanthum gum and Guar gum in different concentrations with propylene glycol as humectant. The prepared gels were checked for physicochemical parameters like $\mathrm{pH}$, dosage form spreadability, tube extrudability, gel viscosity, drug content, in vitro \% drug release, antimicrobial studies and stability studies. FTIR studies showed no interaction between drug, polymer, and other excipients. In vitro \% drug release studies were carried out in diffusion cell using pH 6.8 phosphate buffer as receptor media. Optimized formulation F10 containing Xanthum gum and Guar gum in ratio 1:1 showed good drug release of $97.2 \%$. Stability studies conducted for optimized formulation at temperature of $40^{\circ} \mathrm{C}$ for period of 3 months as per ICH guidelines.
\end{abstract}

Key words: Metronidazole, Chitosan, Xanthum gum and Guar gum.

\section{INTRODUCTION:}

Dental diseases are the most common widespread chronic disorders affecting to mankind. The incidence rate is high with caries and periodontal (gum) diseases which are major problems among the diseases of the oral cavity. The Periodontal disease generally includes several diseases associated with the periodontium. Changes in the microbial flora, histopathological conditions variations, clinical evidential symptoms and inflammation location help to further delineate periodontal disease (Rehaman S et al 2003 and Bou-Chacra NA et al 2005). Periodontitis a more severe stage of dental disease which is characterized by the loss of bone and collagen support of the affected teeth [1]. The common causative organisms Actinobacillus, actinomycete mcomitans is responsible for juvenile periodontitis, while Staphylococci subspecies epidermidis and aureus are responsible for adult periodontal disease. The clinical feature of the periodontal disease is the deepened sulcus i.e, formation of a periodontal pocket. In normal sulcus, is between 1 and $3 \mathrm{~mm}$ deep (Chandrakanth Kokare et al 2010), however in periodontitis, the depth exceeds $5 \mathrm{~mm}$. Treatment of Periodontal disease aims with a localized drug delivery system of therapeutic agent with sufficient level of drug inside the pockets of periodontitis and at the same time less side effects with systemic drug route of 
administration. Hence antimicrobial agents containing drug delivery systems are used for the periodontal pocket treatment (Davies RM et al 2004 and Fathima S et al 2000). The antimicrobial agent for treatment of periodontitis as topical agents is generally preferred as it provides direct access of better local drug concentration of antimicrobial agents.

Hydrogels used as vehicles for different types of pharmaceutical applications and formed from natural, synthetic and semi-synthetic polymers. They have good properties like viscosity, bioadhesion, and are without irritating . Dental gels have been used over the decades either for cosmetics or therapeutic purpose and are generally considered for the treatment to teeth, which is in large part owing to the porous composition of teeth (Okpalugo. J 2009). A dental gel is a dentifrice, used along with a toothbrush, to clean and maintain the aesthetics and health of teeth. Dental gels possess good spreadability, consistency and hence accepted by large population. Most dental gels are chemically designed to effectively penetrate the teeth to strengthen or whiten them or to dull pain (Patel Tarun K, Patel Vishnu M 2013)). Metronidazole is an important active substance that has been widely used in the treatment of some protozoal and anaerobic bacterial infections. For cases that persist after oral treatment and where resistant trichomonads are suspected, a combination of oral and topical therapy may be effective. So antibacterial gels of Metronidazole were prepared by dispersion method, using a blend of natural polymers such as Chitosan, Xanthum gum and Guar gum. The objective of the study is to investigate the effect on the release characteristics of the Metronidazole (antibacterial) gels.

\section{MATERIALS AND METHODOLOGY}

Metronidazole, Chitosan, Xanthum gum, Guar gum, Lactic acid, Silicon dioxide, Sodium fluoride, Sodium lauryl sulphate, Propylene glycol, Sodium saccharin, Titanium dioxide, Menthol, Methyl paraben.

Preparation of Standard Graph: A Standard graph of pure drug in suitable medium was prepared by plotting the concentration on $\mathrm{X}$ axis and absorbance on Y-axis.

Procedure for preparation of standard graph: The standard stock solution was freshly prepared by dissolving $100 \mathrm{mg}$ of metronidazole taken in $100 \mathrm{~mL}$ volumetric flask and dissolve it in a small amount of water initially and make up to $100 \mathrm{ml}$ with water in volumetric flask obtaining the solution strength of $1000 \mu \mathrm{g} / \mathrm{mL}$ (stock1). $10 \mathrm{ml}$ of this solution is diluted to $100 \mathrm{~mL}$ with distilled water to obtain a solution strength of $100 \mu \mathrm{g} / \mathrm{mL}$ (stock2). From this secondary stock 2, 4, 6 and 8 and from primary stock 1.2 and $1.4 \mathrm{~mL}$ was taken and made upto $10 \mathrm{~mL}$ with water to obtain solution strength of 20 , 40, 60, 80, 120 and $140 \mu \mathrm{g} / \mathrm{mL}$ respectively. These solutions were checked for their absorbance using UV-visible spectrophotometer at $\lambda \max 320 \mathrm{~nm}$ against phosphate buffer $6.8 \mathrm{pH}$ as blank and standard graph was plotted.

\section{Preparation of Metronidazole Dental Gel}

Preparation of Chitosan gels: Chitosan at different concentrations chosen to prepare gels with diluted lactic acid (2\%) using a mechanical stirrer. Required concentration Metronidazole was incorporated in the formulations of by mechanical stirring.

Preparation of Guar gum and Xanthum gum gels: For gels dissolving with guar gum, xanthum gum was used hot water, in addition to mechanical stirring. Required 
Table 1: Composition of dental gel formulations F1 to F14

\begin{tabular}{|l|l|l|l|l|l|l|l|l|l|l|l|l|l|l|}
\hline Ingredients (gm) & F1 & F2 & F3 & F4 & F5 & F6 & F7 & F8 & F9 & F10 & F11 & F12 & F13 & F14 \\
\hline Metronidazole & 0.25 & 0.25 & 0.25 & 0.25 & 0.25 & 0.25 & 0.25 & 0.25 & 0.25 & 0.25 & 0.25 & 0.25 & 0.25 & 0.25 \\
\hline Chitosan & 0.5 & 1 & 2 & - & - & - & - & - & - & - & - & - & 1 & 1 \\
\hline Xanthum gum & - & - & - & 0.5 & 1 & 2 & - & - & - & 1 & 2 & 1 & 1 & - \\
\hline Guar gum & - & - & - & - & - & - & 0.5 & 1 & 2 & 1 & 1 & 2 & - & 1 \\
\hline Lactic acid & 2 & 2 & 2 & - & - & - & - & - & - & - & - & - & 2 & 2 \\
\hline Silicon dioxide & 10 & 10 & 10 & 10 & 10 & 10 & 10 & 10 & 10 & 10 & 10 & 10 & 10 & 10 \\
\hline Sodium fluoride & 0.35 & 0.35 & 0.35 & 0.35 & 0.35 & 0.35 & 0.35 & 0.35 & 0.35 & 0.35 & 0.35 & 0.35 & 0.35 & 0.35 \\
\hline Sodium lauryl sulphate & 1 & 1 & 1 & 1 & 1 & 1 & 1 & 1 & 1 & 1 & 1 & 1 & 1 & 1 \\
\hline Propylene glycol & 5 & 5 & 5 & 5 & 5 & 5 & 5 & 5 & 5 & 5 & 5 & 5 & 5 & 5 \\
\hline Sodium saccharin & 0.1 & 0.1 & 0.1 & 0.1 & 0.1 & 0.1 & 0.1 & 0.1 & 0.1 & 0.1 & 0.1 & 0.1 & 0.1 & 0.1 \\
\hline Titanium dioxide & 0.2 & 0.2 & 0.2 & 0.2 & 0.2 & 0.2 & 0.2 & 0.2 & 0.2 & 0.2 & 0.2 & 0.2 & 0.2 & 0.2 \\
\hline Menthol & 0.5 & 0.5 & 0.5 & 0.5 & 0.5 & 0.5 & 0.5 & 0.5 & 0.5 & 0.5 & 0.5 & 0.5 & 0.5 & 0.5 \\
\hline Methyl paraben & 0.03 & 0.03 & 0.03 & 0.03 & 0.03 & 0.03 & 0.03 & 0.03 & 0.03 & 0.03 & 0.03 & 0.03 & 0.03 & 0.03 \\
\hline Water & q.s & q.s & q.s & q.s & q.s & q.s & q.s & q.s & q.s & q.s & q.s & q.s & q.s & q.s \\
\hline
\end{tabular}

concentration metronidazole was combined in the formulations.

\section{Evaluation of medicated dental gel}

Different evaluation studies were performed for all the prepared gel formulation to check wheather these preparations have met the specifications as given in U.S.P.

Various In vitro tests performed are Visual determination, Determination of $\mathrm{pH}$, Spreadability test, Tube extrudability test, Viscosity and rheological behavior, Drug content determination, In vitro release studies, Stability Studies.

Visual examination: All developed gel dosage forms were inspected visually for their product homogenity, colour appearance and lumps presence after the gel preparations have been set in suitable container.

Determination of $\mathrm{pH}$ : The $\mathrm{pH}$ of the prepared medicated dental gel formulation was determined after the preparation of gel using a digital glass electrode $\mathrm{pH}$ meter. $\mathrm{pH}$ was noted by bringing the electrode near the surface of the formulations and allowing it to equilibrate for $1 \mathrm{~min}$. (Shiva Kumar Yellanki et al., 2010)
Spreadability test: Spreadability is the term expressed to describe the extent of area to which the gel readily spreads on application to the teeth.

One gram of sample from each formulae was placed between two glass slides $(10 \times 10 \mathrm{~cm})$, and left for 5 minutes where no more further spreading was expected. Diameters of spreaded area circles drawn were measured were taken in $\mathrm{cm}$ as comparative values for spreadability. The obtained results were average of three times determinations. (Doaa A. helal et al., 2012)

The spreadability (S) can be calculated formula mentioned below

$\mathrm{S}=\mathrm{d} 2-\mathrm{d} 1$

Where,

S - Spreadability.

d1 - Initial diameter of gel when placed on glass slide

d2 - Final diameter of gel after spreading

Tube extrudaility test: This test used to measure the force required to gel extrusion from collapsible tubes when certain force has 
been applied. In present study the quantity of gel extruded in percentage from the tube on application of force was observed. More the quantity extruded, better was the extrudability.

The formulated preparations were filled in standard capped aluminium collapsible tubes with a nasal tip of $5 \mathrm{~mm}$ opening and crimping sealed ends. The tubes weight was recorded and then applied pressure on tube with finger. Determined tube extrudability by measuring the amount of gel extruded when pressure was applied on tip of tube. (Vidya, N. Dange et al., 2014)

Tube extrudability $=\underline{\text { Extruded gel } \times 100}$

Initial amount of gel

The percent of gel extruded was calculated, and graded as follows: $90 \%++++$ excellent; $80 \%+++$ good; $70 \%++$ fair; $50 \%$ + poor.

Viscosity and rheological behavior: The gel viscosity was determined by a Brookfield Viscometer DVII model with a T- Bar spindle in combination with a helipath stand.

Section of spindle: Spindle (T 64) was selected for the all the gels viscosity measurement.

Sample container size: $50 \mathrm{~g}$ gel filled in a $100 \mathrm{~mL}$ beaker for measurement of viscosity.

Spindle immersion: The T -bar spindle (T 64) was lowered perpendicular in the center taking care that spindle does not touch bottom of the jar.

Measurement of viscosity: Selected the T - bar spindle (T64) for determining the gel viscosity. The factors like sample size, pressure and temperature etc., which affect the viscosity was maintained during the process. The helipath $\mathrm{T}$ - bar spindle was moved up and down giving viscosity at number of points along the path.
Drug content determination: The drug content was determined by dissolving accurately weighed $100 \mathrm{mg}$ of formulation in phosphate buffer 6.8 using magnetic stirrer for 3 hours in order to complete solubility of the drug. The solution was filtered through whatman filter paper $(0.45 \mu)$. The solutions were subjected to centrifugation at $15000 \mathrm{rpm}$ for $15 \mathrm{~min}$. The resulting solution was then separated and supernatant liquid was collected. The collected supernatant was then diluted approximately and estimated using UV-Visible spectrophotometer at $320 \mathrm{~nm}$

Drug content $=$ Concn $\times$ Dilution factor $\times$ Vol. of buffer taken

1000

In vitro Drug Release Studies: A modified Franz diffusion cell with standard gelatin membrane used for checking the in vitro drug releases from medicated dental gels. Prior to study in diffusion medium gelatin membrane was soaked for $4 \mathrm{hrs}$ and placed between two compartments of cell. Donor compartment filled with the prepared gel about $1 \mathrm{gm}$ and receiver compartment was filled with $6.8 \mathrm{pH}$ phosphate buffer $(25 \mathrm{~mL})$. Calculated the active diffusion area as $4.17 \mathrm{~cm}^{2}$. All the joints of diffusion cell were properly sealed with the help of a clamp to avoid the diffusion medium penetration. The receiver compartment placed on magnetic stir bar which was stirred at $500 \mathrm{rpm}$ and a $2 \mathrm{~mm}$ width. Intermittent of $5 \mathrm{~mL}$ samples were withdrawn from receiver compartment at every $5 \mathrm{~min}$ and for every half an hour and the drug transported amount was measured. Equal volume of aliquot buffer was replenished in the receiver compartment after each sampling. The sample solutions were diluted with $6.8 \mathrm{pH}$ phosphate buffer to measure the absorbance of the solutions using UV - spectrophotometer at $320 \mathrm{~nm}$. 
Stability studies: The stability studies of optimized gel formulation were carried out at different temperatures for 3 months at $4^{\circ} \mathrm{C} \pm$ $2^{\circ} \mathrm{C} \pm 0.5^{\circ} \mathrm{C}(60 \% \mathrm{RH})$ and $40^{\circ} \mathrm{C} \pm 0.5^{\circ} \mathrm{C}(75 \%$ $\mathrm{RH})$. The gel formulations were kept in a stability chamber (Thermo labs scientific equipments, Vaagdevi College) for $25^{\circ} \mathrm{C}, 40^{\circ} \mathrm{C}$ and at $4 \pm 2^{0} \mathrm{C}$ in refrigerator for 3 months. At the end of 1 and 3 months, the gels were evaluated for their colour, Spreadability, Extrudability, Viscosity, pH, Drug content and in vitro diffusion study.

\section{RESULTS AND DISCUSSION}

The prepared Metronidazole dental gels were evaluated to obtain maximum release of the drug at the administered site of action in order to increase the bioavailability and decrease the side effects.

Standard graph of Metronidazole: Calibration curve of Metronidazole was based on general procedure. Metronidazole calibration curve was developed by scanning $20 \mu \mathrm{g} / \mathrm{mL}$ solution of buffer $6.8 \mathrm{pH}$. Metronidazole exhibited $\lambda_{\max }$ a 320nm. Figure 1 describes the standard graph of Metronidazole in 6.8 $\mathrm{pH}$ phosphate buffer. The correlation coefficient of standard curve was found to be linear (0.998). For the diffusion study and drug content determination, the phosphate buffer 6.8 was complied.

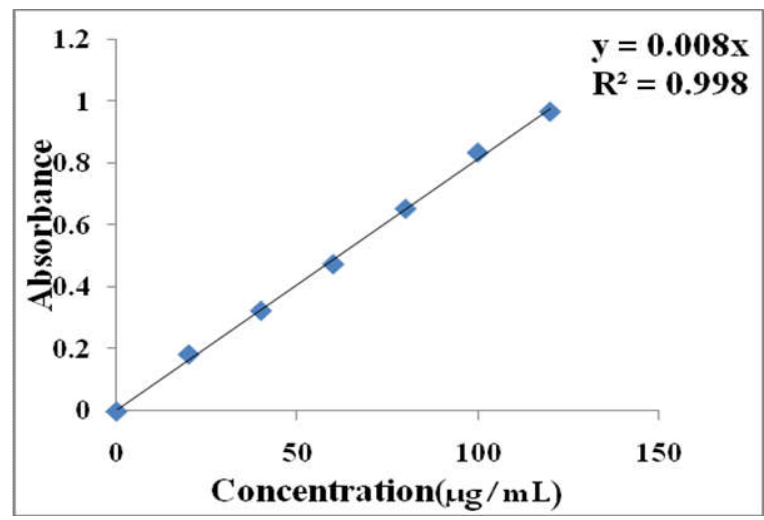

Fig 1: Standard graph of Metronidazole in $6.8 \mathrm{pH}$ phosphate buffer

All the $\mathrm{pH}$ formulations were found to be in the range of 6.0-6.7 which are similar to $\mathrm{pH}$ www.ijapbjournal.com range of buccal cavity 6 to 7, so the prepared dental gels will be free from irritation. The spreadabilty determined to be in the range of 5.2-7.1 g-cm/sec which confirming that the gels may spread on teeth with smooth and uniform. Tube extrudability values were in the range of $72-85 \%$. The gel was pass easily through the tube and there was no much variations in extrudability depending on the polymer concentration and propylene glycol. The gel viscosity increased with gelling agent concentrations enhancement. Drug content of dental gel formulations were in the range of 85 to $98 \%$. Metronidazole indicating good content uniformity in all the formulations means drug was uniformly distributed throughout the gel.

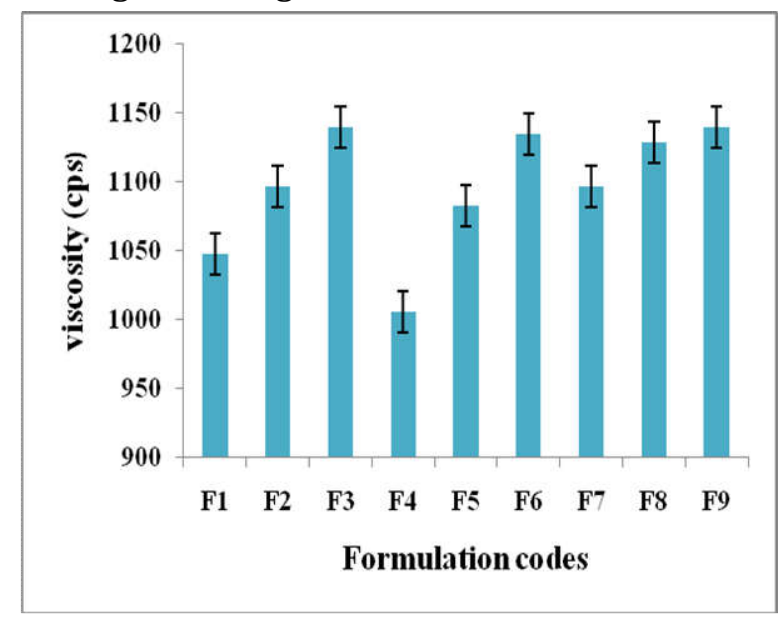

Fig 2: Viscosity of dental gel formulation F1-9

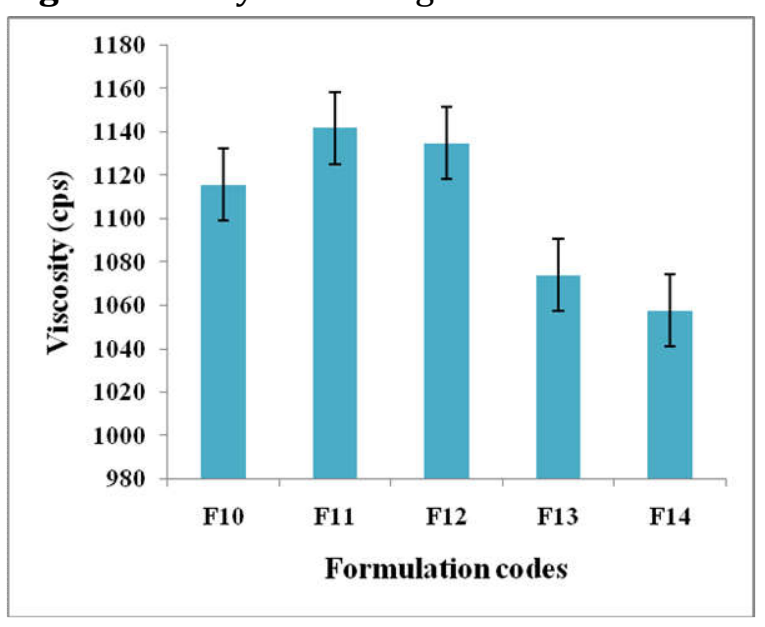

Fig 3: Viscosity of dental gel formulation F1014. 


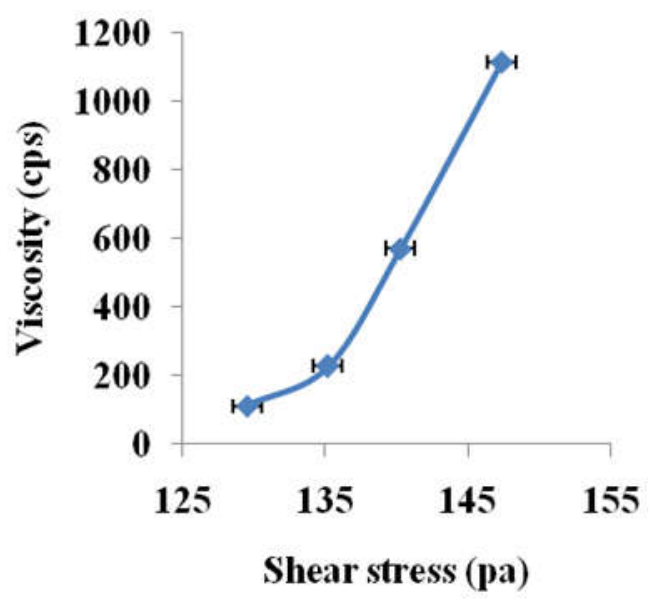

Fig.4: Viscogram of optimized gel F10

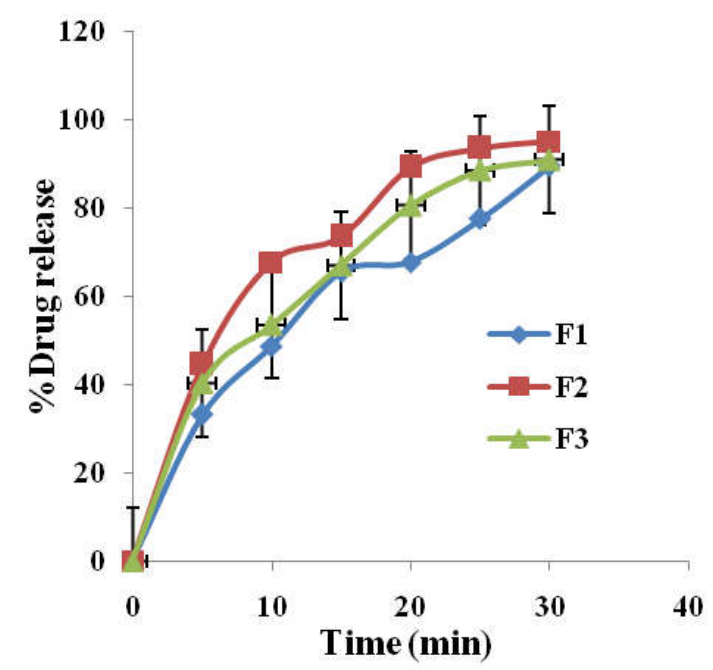

Fig 5: \%Drug release of gel F1-F3

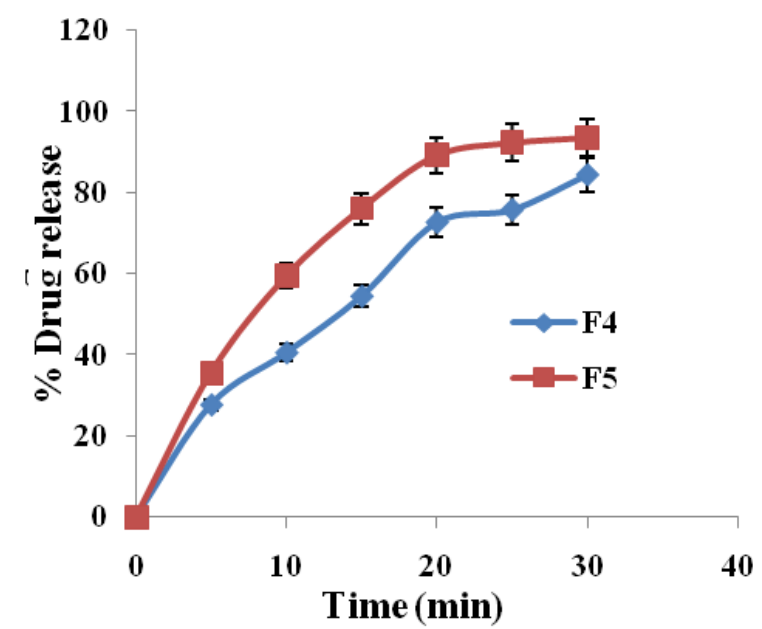

Fig 6: \%Drug release of gel F4-F6

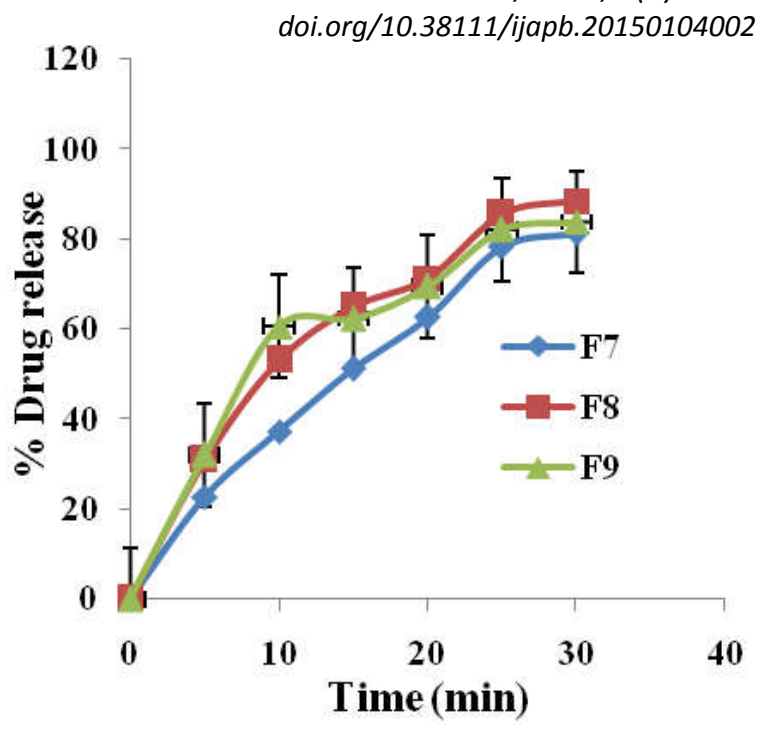

Fig 7: \%Drug release of gel F7-F9

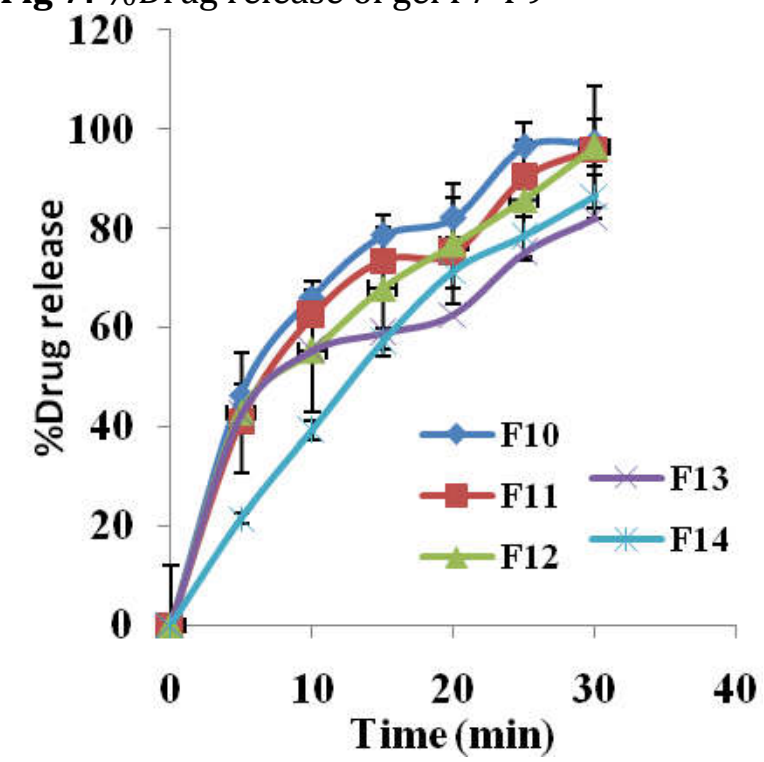

Fig 8: \%Drug release of gel F10-F14

In vitro drug release of the dental gel dosage forms was found to be within the ranges of 81.42\%- 97.2\%. The dental gel F10 formulated using xanthum gum and guar gum in ratio 1:1 showed highest drug release of $97.2 \%$ and were consider as best formulation.

\section{CONCLUSION}

Metronidazole dental gel was prepared with an objective to protect the gums, teeth and oral cavity from periodontal infections and Dental caries. Preformulation studies like solubility and UV analysis of Metronidazole were complied with standards FTIR spectral analysis revealed absence interaction 
between drug and polymer. The polymers use is compatible with the Metronidazole. Oral immediate release of Metronidazole can be achieved by dispersion method by using different natural bio-degradable polymers of different concentrations and it is effective against inhibiting oral flora.

\section{ACKNOWLEDGEMENT}

Authors are thankful to the Principal and Secretary, Vaagdevi college of Pharmacy, for providing necessary facilities and actions towards the fruitful completion of this research work.

\section{CONFLICT OF INTEREST}

The author(s) confirm that this article content has no conflict of interest.

\section{REFERENCES}

[1] Rehaman S, Ashiya A, Khar RK. "Site Specific Delivery System for the treatment of Periodontitis. Indian J Pharma Sci 2003. p. 106-112.

[2] Bou-Chacra NA, Gobi SS, Ohara MT, Pinto TJA. Antimicrobial activityof four different dental gel formulas on cariogenic bacteria evaluated using the linear regression method. Revista Brasileira De Ciencias Farmaceuticas 2005; 41(3):323-31

[3] Chandrakanth Kokare. Pharmaceutical Microbiology Experiments And Techniques, Career Publication, Edition3: 2010; 197-202.

[4] Davies RM, Ellwood RP, Davies GM "The effectiveness of a toothpaste containing triclosan and polyvinyl-methyl ether doi.org/10.38111/ijapb.20150104002

maleic acid copolymer in improving plaque control and gingival health". Journal of Clinical Periodontology. 2004; 31(12): 1029-33.

[5] Fatima S, Farooqi AH, Kumar R, Kumar TR, Khanuja SP. Antibacterial activity possessed by medicinal plants used in tooth powder. J. Med. Arom. Pl. Sci. 2000; 22:187-189

[6] Okpalugo. J, "Toothpaste formulation efficacy in reducing oral flora". Topical Journal of Pharmaceutical Research. 2009; 8(1): 71-77.

[7] Patel Tarun K, Patel Vishnu M. "Formulation and evaluation of medicated dental paste for periodontal infection". International Journal of Pharmaceutical Innovations. 2013; 3(2): 1-10.

[8] Shiva Kumar Yellanki. "Formulation, Characterization and Evaluation of Metronidazole gel for local treatment of Periodontitis". International Journal of Pharma and Bio Sciences. 2010;.2: 1-9.

[9] Doaa a. Helal., Dalia abd el-rhman., Sally a. Abdel-halim., Mohamed a. El-nabarawi. Formulation And Evaluation of Fluconazole Topical Gel International Journal of Pharmacy and Pharmaceutical Sciences 2012 4(5), 176-183

[10] Vidya. N. Dange, Chandrakant.s. Magdum, Shrinivas.K.mohite, Manoj. M. Nitalikar, miss shubhangi j.shid. Formulation and evaluation of cetylpyridinium chloride toothpaste International journal of universal pharmacy and bio sciences 3(6): 2014; 68-78.

\section{How to cite this article:}

Yaswanth Kumar K et al Evaluation of Biochemical Markers for Bone Changes in Leprosy Patients. Int. J. Adv. Pharm. Biotech., 2018; 4(3): 1-5. 


\begin{tabular}{|c|l|c|c|c|c|}
\hline Formulation & pH & Spreadability (g-cm/sec) & $\begin{array}{c}\text { Extrudability } \\
\text { (\%) }\end{array}$ & $\begin{array}{l}\text { Viscosity } \\
\text { (cps) }\end{array}$ & Drug content(\%) \\
\hline F1 & $6.1 \pm 0.15$ & $7.1 \pm 0.12$ & $83 \pm 1.7$ & $1048 \pm 1.12$ & $90 \pm 0.92$ \\
\hline F2 & $6.0 \pm 0.31$ & $7.0 \pm 0.22$ & $82 \pm 1.3$ & $1097 \pm 1.15$ & $96 \pm 0.57$ \\
\hline F3 & $6.7 \pm 0.21$ & $6.2 \pm 0.14$ & $79 \pm 1.0$ & $1140 \pm 1.53$ & $93 \pm 0.28$ \\
\hline F4 & $6.3 \pm 0.11$ & $7.0 \pm 0.23$ & $85 \pm 1.5$ & $1006 \pm 1.10$ & $89 \pm 0.93$ \\
\hline F5 & $6.2 \pm 0.13$ & $6.9 \pm 0.35$ & $83 \pm 1.6$ & $1083 \pm 1.22$ & $94 \pm 0.33$ \\
\hline F6 & $6.5 \pm 0.15$ & $5.9 \pm 0.25$ & $79 \pm 1.2$ & $1135 \pm 2.13$ & $95 \pm 0.56$ \\
\hline F7 & $6.6 \pm 0.10$ & $6.8 \pm 0.10$ & $81 \pm 1.4$ & $1097 \pm 1.28$ & $85 \pm 0.52$ \\
\hline F8 & $6.3 \pm 0.32$ & $5.7 \pm 0.13$ & $75 \pm 1.6$ & $1129 \pm 1.31$ & $91 \pm 0.43$ \\
\hline F9 & $6.2 \pm 0.14$ & $5.4 \pm 0.15$ & $73 \pm 1.0$ & $1140 \pm 1.48$ & $88 \pm 0.73$ \\
\hline F10 & $6.6 \pm 0.16$ & $6.5 \pm 0.24$ & $80 \pm 1.5$ & $1116 \pm 1.29$ & $98 \pm 0.68$ \\
\hline F11 & $6.1 \pm 0.22$ & $5.2 \pm 0.25$ & $72 \pm 1.2$ & $1142 \pm 2.32$ & $97 \pm 0.52$ \\
\hline F12 & $6.2 \pm 0.18$ & $5.5 \pm 0.16$ & $76 \pm 1.3$ & $1135 \pm 2.11$ & $97 \pm 0.62$ \\
\hline F13 & $6.4 \pm 0.23$ & $6.0 \pm 0.12$ & $75 \pm 1.1$ & $1074 \pm 1.19$ & $87 \pm 0.73$ \\
\hline F14 & $6.2 \pm 0.15$ & $6.4 \pm 0.17$ & $77 \pm 1.5$ & $1058 \pm 1.17$ & $93 \pm 0.25$ \\
\hline
\end{tabular}

Table 5: Cumulative percent drug release of formulations (F1-F7)

\begin{tabular}{|c|l|l|l|l|l|l|l|}
\hline Time (min) & \multicolumn{1}{|c|}{ F1 } & \multicolumn{1}{|c|}{ F2 } & \multicolumn{1}{|c|}{ F3 } & \multicolumn{1}{|c|}{ F4 } & \multicolumn{1}{|c|}{ F6 } & \multicolumn{1}{|c|}{ F7 } \\
\hline $\mathbf{5}$ & $33.21 \pm 1.1$ & $44.64 \pm 0.7$ & $40.42 \pm 1.5$ & $27.8 \pm 0.8$ & $35.67 \pm 1.2$ & $36.2 \pm 0.9$ & $22.85 \pm 0.8$ \\
\hline $\mathbf{1 0}$ & $48.8 \pm 1.4$ & $67.85 \pm 1.5$ & $53.57 \pm 1.3$ & $40.61 \pm 1.1$ & $59.52 \pm 0.6$ & $47.91 \pm 1.6$ & $37.42 \pm 0.3$ \\
\hline $\mathbf{1 5}$ & $65.6 \pm 0.8$ & $73.57 \pm 1.3$ & $67.14 \pm 1.0$ & $54.5 \pm 1.5$ & $76.2 \pm 0.9$ & $69.56 \pm 0.3$ & $51.2 \pm 0.6$ \\
\hline $\mathbf{2 0}$ & $67.85 \pm 0.6$ & $89.28 \pm 1.1$ & $80.71 \pm 0.7$ & $72.7 \pm 0.1$ & $89.28 \pm 1.1$ & $78.57 \pm 0.4$ & $62.8 \pm 0.5$ \\
\hline $\mathbf{2 5}$ & $77.6 \pm 0.7$ & $93.62 \pm 1.5$ & $88.6 \pm 0.6$ & $75.8 \pm 0.5$ & $92.36 \pm 0.2$ & $87.51 \pm 1.1$ & $78.36 \pm 0.1$ \\
\hline $\mathbf{3 0}$ & $89.72 \pm 1.1$ & $95.13 \pm 0.7$ & $91.07 \pm 1.4$ & $84.4 \pm 1.0$ & $93.65 \pm 0.6$ & $91.2 \pm 1.2$ & $81.42 \pm 0.3$ \\
\hline Flux & 249 & 352 & 249 & 344 & 326 & 206 & 249 \\
\hline
\end{tabular}

Table 6: Cumulative percentage drug release of formulations (F8-F14)

\begin{tabular}{|c|l|l|l|l|l|l|l|}
\hline Time (min) & \multicolumn{1}{|c|}{ F8 } & \multicolumn{1}{c|}{ F9 } & \multicolumn{1}{|c|}{ F10 } & \multicolumn{1}{|c|}{ F11 } & \multicolumn{1}{|c|}{ F12 } & \multicolumn{1}{c|}{ F13 } & \multicolumn{1}{c|}{ F14 } \\
\hline $\mathbf{5}$ & $31.07 \pm 1.2$ & $32.14 \pm 1.0$ & $46.42 \pm 0.5$ & $41.07 \pm 1.3$ & $42.85 \pm 0.8$ & $42.41 \pm 0.6$ & $21.42 \pm 0.9$ \\
\hline $\mathbf{1 0}$ & $53.21 \pm 0.7$ & $60.71 \pm 1.4$ & $66.07 \pm 0.8$ & $62.42 \pm 0.4$ & $55.28 \pm 1.5$ & $55.35 \pm 0.3$ & $39.28 \pm 1.1$ \\
\hline $\mathbf{1 5}$ & $65 \pm 0.4$ & $62.42 \pm 0.2$ & $78.57 \pm 0.2$ & $73.5 \pm 0.3$ & $67.85 \pm 0.2$ & $58.92 \pm 0.5$ & $57.14 \pm 1.4$ \\
\hline $\mathbf{2 0}$ & $71.42 \pm 1.6$ & $69.57 \pm 0.9$ & $82.14 \pm 1.4$ & $75 \pm 1.5$ & $76.87 \pm 1.1$ & $62.5 \pm 1.3$ & $71.4 \pm 1.2$ \\
\hline $\mathbf{2 5}$ & $85.71 \pm 0.3$ & $82.14 \pm 1.5$ & $96.42 \pm 0.6$ & $90.21 \pm 0.2$ & $85.71 \pm 1.3$ & $75 \pm 1.2$ & $78.3 \pm 0.6$ \\
\hline $\mathbf{3 0}$ & $88.57 \pm 0.8$ & $83.92 \pm 0.4$ & $97.2 \pm 0.8$ & $96 \pm 1.0$ & $95.42 \pm 0.9$ & $82.14 \pm 0.7$ & $86.42 \pm 1.4$ \\
\hline Flux & 266 & 318 & 215 & 249 & 275 & 206 & 344 \\
\hline
\end{tabular}

